\title{
Homogeneously Staining Region
}

National Cancer Institute

\section{Source}

National Cancer Institute. Homogeneously Staining Region. NCI Thesaurus. Code C6832.

A region on a chromosome which, when stained, is uniform in appearance. (Normally, a stained chromosome shows a banding pattern.) Homogeneously staining regions contain multiple copies of a single gene. (Online Medical Dictionary) 